\title{
The ultrastructure of knobbed bull spermatozoa
}

\author{
D. G. Cran and H. M. Dott \\ A.R.C. Unit of Reproductive Physiology and Biochemistry, \\ University of Cambridge, U.K.*
}

A defect of the sperm acrosome, called 'knobbing' has been associated with sterility in the bull (Teunissen, 1946; Blom, 1948; Hancock, 1952; Donald \& Hancock, 1953; Blom \& Birch-Andersen, 1962; Blom, 1972), and boar (Bane, 1961), and has been seen in stallion (Dott, 1975), ram, dog and impala (unpublished).

Donald \& Hancock (1953) came to the conclusion that this was an autosomal sex-linked recessive characteristic in Friesian bulls. At the level of the light microscope it is seen as an apical, often eccentric swelling which folds back over the head. Blom \& Birch-Andersen (1962) described this character as a swelling of the apical body to six to eight times normal. Much of the region was cystic and contained vesicles with inclusions. The ultrastructure of this defect in Friesian bulls is described in the present paper.

Semen was collected in an artificial vagina from a bull with a high proportion of affected spermatozoa and fixed in formalin-picric acid-glutaraldehyde (Jones, 1973b) or tannic acid (Roomans, 1975). The spermatozoa were subjected to gentle centrifugation during the various procedures. The samples were embedded in Epon and examined in an AEI 801 microscope.

Although cystic forms (Blom \& Birch-Andersen, 1962; Blom, 1972) were detected (PI. 1, Fig. 1), they were not common. The most common type was that in which the acrosomal swelling lay along the top of the spermatozoon (PI. 1, Fig. 2). It was about 3 times as long as it was thick and had normal acrosomal density. A pouch running parallel to the outer border was frequently present along the outer edge, and occasionally opened to the exterior (Pl. 1, Fig. 3). Small vesicles, clearly originating from the outer acrosomal membrane were sometimes found adjacent to the nucleus. Often there was a thinning of the acrosome posterior to the knob and indications of a perforatorium were only occasionally seen.

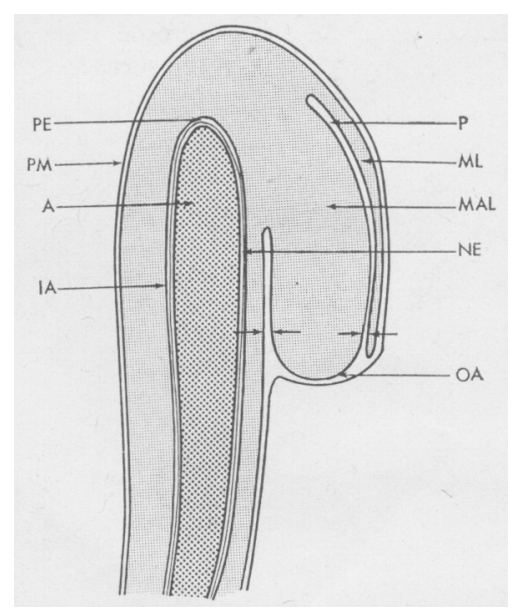

Text-fig. 1. Diagram showing the morphology of knobbed spermatozoa from a Friesian bull. Areas in which membrane fusion may take place are indicated by unlabelled arrows. A, acrosome; IA, inner acrosomal membrane; ML, minor lobe; MAL, major lobe; N, nucleus; NE, nuclear envelope; OA, outer acrosomal membrane; $P$, pouch; PE, region of perforatorium; PM, plasma membrane.

* Postal address: Animal Research Station, 307 Huntingdon Road, Cambridge CB3 0JQ, U.K. 
On the basis of observations on numerous longitudinal sections of the apical region of such spermatozoa, a generalized morphological description may be obtained (Text-fig. 1). The apical acrosomal extension comprises two lobes, an inner major and outer minor. They are both bounded by the outer acrosomal membrane which is, in turn, surrounded by the plasma membrane. It is most likely that the posterior portion of the minor lobe frequently fuses with that of the major resulting in a long vesicle. It is also likely that a dilatation of this resulted in the cystic form seen by Blom \& BirchAndersen (1962) and Blom (1972). Membrane fusion may also take place between the membrane investing the inner portion of the major lobe and that part of the acrosome surrounding the nucleus, resulting in scattered vesicles as described by Jones (1973a).

Occasional departures from the form described may be found. These generally result from the incomplete formation of one of the lobes. In cases in which the inner lobe failed to form, the outer lobe was very much prolonged and took up a convoluted configuration. In the other case, a simple lobe was present or an extension from it replaced the minor lobe.

One of the authors (H.M.D.) is grateful to the C.S.I.R. and the Mammal Research Institute, Pretoria, South Africa for funds and facilities for collection of material.

\section{References}

BANE, A. (1961) Acrosomal abnormality associated with sterility in boar. Proc. 4th Int. Congr. Anim. Reprod. \& A.I., The Hague pp. 810-817.

BLom, E. (1948) Om Spermaundersogelzesmetoder has Tyren. Medlesmbl. danske Dyrlaegeforen. 31, $446-462$.

BLom, E. (1972) The ultrastructure of some characteristic sperm defects and a proposal for a new classification of the bull spermiogram. Proc. 7th Symp. Int. Zootec., Milan pp. 125-139.

BLom, E. \& BIRCH-ANDERSEN, A. (1962) Ultrastructure of the sterilizing knobbed sperm defect in the bull. Nature, Lond. 194, 989-990.

Donald, H.P. \& HaNCOCK, J.L. (1953) Evidence of gene-controlled sterility in bul!s. J. agric. Sci., Camb. 43, 178-181.
Dotr, H.M. (1975) Morphology of stallion spermatozoa. J. Reprod. Fert., Suppl. 23, 41-46.

HANCOCK, J.L. (1952) The spermatozoa of sterile bulls. Proc. 2nd Int. Congr. Physiol. Path. Anim. Reprod. \& A.I., Copenhagen pp. 35-40.

JONES, R.C. (1973a) Changes occurring in the head of boar spermatozoa: vesiculation or vacuolation of the acrosome? J. Reprod. Fert. 33, 113-118.

JoNES, R.C. (1973b) Preparation of spermatozoa for electron and light microscopy. J. Reprod. Fert. 33, 145-149.

Roomans, G.M. (1975) Tannic acid fixation of human spermatozoa. J. Reprod. Fert. 43, 197-200.

TeUNISSEN, G.H.B. (1946) Een afwijking van het acrosoom (kopkap) bij ale spermatozoidem van een stier. Tijdschr. Diergeneesk. 71, 292-301. 
PLATE 1
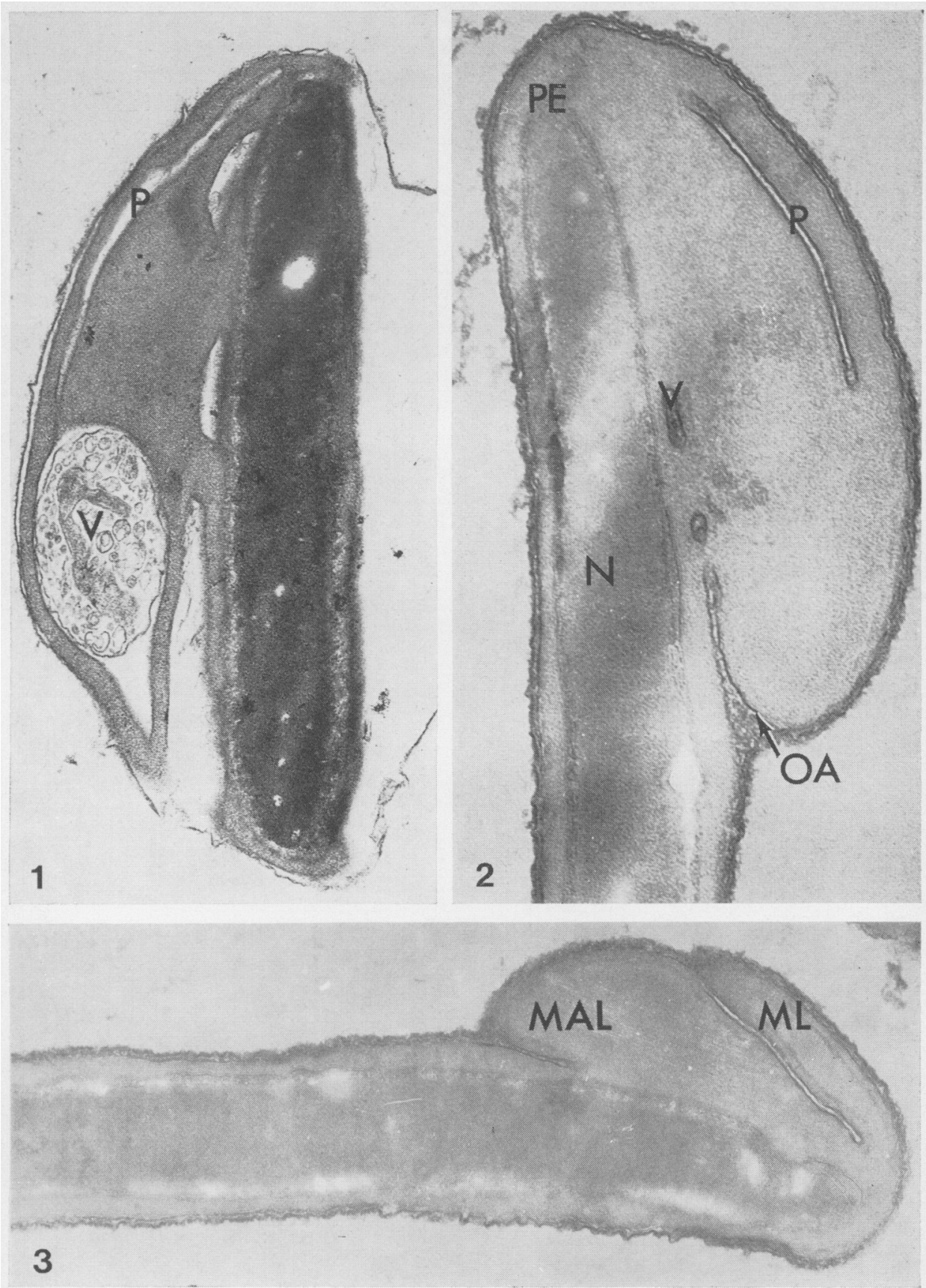

Knobbed spermatozoa from a Friesian bull.

Fig. 1. An oblique section through the apex. The pouch (P) is partly dilated and contains a vesicle (V) with membranous contents similar to those of a cytoplasmic droplet. $\times 64,000$.

Fig. 2. A longitudinal section showing the acrosomal swelling bent back over the head of the spermatozoon. A blind pouch $(P)$ is present close to the exterior, and vesicles $(V)$ which may result from the fusion of the outer acrosomal membrane (OA) are present close to the nucleus $(\mathrm{N})$. The perforatorium (PE) is limited. $\times 104,000$.

Fig. 3. A longitudinal section clearly demonstrating the presence of two lobes (ML, minor lobe; major lobe). In this case the pouch appears to open to the exterior. $\times 68,000$.

(Facing p. 408) 